\title{
Energy shame
}

\section{The history of energy research highlights the importance and inadequacies of markets, and a yawning gap in the priorities of governments. It's time for a radical change.}

F rances Cairncross, chair of Britain's Economic and Social Research Council, has been thinking about the economics of climate change longer than most natural scientists and economists. In her presidential address to the annual meeting of the British Association for the Advancement of Science this week, she rightly emphasized one of the most important things that governments can do: invigorate and focus research into the basic and translational science needed for new energy-conversion technologies.

Solar power is a case in point. Its great economic attraction is that, unlike nuclear power or carbon capture and storage, it does not need vast capital investment in order to spread. Its products just need to be priced in such a way that consumers and companies want to buy them. Once that point is reached, a solar-cell factory can produce the capacity to generate electricity as easily as a power station does, thus offering the possibility of exponential growth.

As we report on page 19, a boom in the solar-energy business, led by Japan and Germany, has now attracted serious interest from, among others, the technologists and venture capitalists of California's Silicon Valley. The people who brought the world Moore's law are eager to help it sustain itself through clean technology while accumulating yet more wealth on the way. Its most vigorous proponents suggest that attracting the attention of high-tech entrepreneurs could in itself be an end to our energy woes - a "distributed Manhattan project that attracts the smartest, most ideal people for the task", as Bill Gross, serial entrepreneur and trustee of the California Institute of Technology, put it to The New York Times earlier this year.

But a healthy respect for the power of entrepreneurs and free markets cannot hide the fact that they do best when choosing between possibilities that are close to market, rather than inventing entirely new options. There is research into new materials and technologies that small start-up companies can't do, and that larger, more staid ones, if history is a guide, won't.

History may not be a guide, of course. But even the possibility that the research may not get done is a reason for government to step in and ensure that it does, while trying not to crowd out private capital in the process. The current solar boom is dependent on old and trusted technologies - the companies now piling in are mostly finding new ways to manufacture and process familiar products. If the current rate of heady growth is to keep going for the quarter-century needed to start making a real change in the world's energy outlook, we will need new materials to capture the Sun's power ever more cheaply and easily, and new solutions to the problem of storing it.

Many scientists are eager to set out in search of those technologies. It is essential that curiosity-led research should flourish in these areas, and that funding bodies should encourage it so to do.

There are also areas where directed research might come into its own - where the best approach may be to try out lots of possibilities, rather than go with what a few bright people think is best. One of the strengths of the Manhattan project was that it tried out as many roads to nuclear weaponry as seemed plausible. Governments need to be willing to take advice on directed research and then make it happen,
"It is to the abiding shame of the world's governments that over the past two decades, funding for energy research has actually fallen." rather than just hoping that curiosity will triumph unaided.

Talk of a Manhattan project to tackle the generation and storage of 'clean' energy may seem overblown. It shouldn't. The challenge of increasing energy use in the developing world while at least stabilizing and ideally decreasing carbon dioxide emissions is immense. It is to the abiding shame of the world's governments that, as the threat to the climate has become ever more apparent over the past two decades, funding for energy research and development has actually fallen. To suggest that spending on energy research should be limited only by the capacity of scientists and technologists to make practical use of it is not to be profligate, but rational.

journey taken to prepare the compound is as important as arriving at the destination. Indeed, chemists are frequently drawn to the field because there is not just one way to solve the problem, and the search can reveal a bit more about how the world works.

When a complex synthesis is first reported at a conference, the excitement can be palpable. The audience can be inspired by the speaker's innovative approach, but there may be another reason for their exhilaration: they might be able to apply the lessons learned from that synthesis to their own research.

An impressive synthesis may be described as 'beautiful' or 'elegant' because of an aesthetic appreciation of the molecule itself or the way it was created. But it often implies that the approach was creative and that the molecule was made efficiently. Because chemists design their no one else has made before. Many spend their days trying to make large, architecturally complex molecules, and some believe that the 
syntheses by looking at the target molecule and working backwards towards simpler starting materials, chemists can impress their peers by pursuing strategies no one else noticed, by using original sequences of previously disparate reactions, or by developing new reactions that enable them to construct bonds in an unexpected way.

The work isn't over when the first synthesis of a complex molecule is reported - there is always plenty of room for improvement, and chemists are fired up by the desire to make things better. Secondgeneration syntheses are often very different from the original, and may have fewer steps or contain new and unexpected chemical reactions. This iterative process is not just an academic exercise: process chemists in pharmaceutical companies are often the unsung heroes of the synthetic world, as they devise incredibly effective syntheses to produce kilogram quantities of potential drugs. By doing so, they save millions of dollars for their companies, and can reduce the environmental impact of the synthesis by minimizing the amounts of waste produced or the quantities of solvents required.

In a similar vein, chemists enjoy finding improved catalysts. Catalysts exist for many reactions but are often expensive, toxic or impractical for anything other than simple molecules. By exploring the chemical mechanism of the catalyst, or perhaps by just plain luck, chemists can develop second-and third-generation catalysts that dramatically outperform the first-generation system. This can be invaluable both in the lab and for improving industrial processes.

A common misconception is that organic chemists now have a complete 'toolbox' of reactions that can be applied to any synthesis. But the toolbox is certainly not full; many desirable reactions remain elusive. This is especially true in the area known as 'asymmetric catalysis', which involves the creation of a chiral material from a nonchiral substrate - molecules can exist in left-hand and right-hand forms, and the development of catalysts that can selectively make one of the two forms is a major challenge in the field. To outsiders, this is a particularly obscure field of work, but the inherent challenges involved attract vast numbers of researchers. Furthermore, the products of these reactions have enormous potential utility, as smallmolecule tools that can tease apart a complex biological system, or as lead compounds that can be developed into the next 'blockbuster' drug. Without asymmetric synthesis, some hugely successful drugs — such as AZT for HIV/AIDS, or lovastatin, which reduces cholesterol - would be extremely difficult to make.

Today, a novice organic chemist is like a child in a sweetshop. There are many 'hot' areas to work on: 'green' chemistry, which seeks ways to eliminate environmentally harmful chemicals from common processes; the burgeoning area of nanotechnology, constructing minuscule components for a future age of molecular devices; or maybe just pushing the boundaries of chemical space, by concentrating on a single element such as boron and seeing what chemistry can be developed. The modern world requires medicines, agrochemicals and advanced materials, and it is chemists who must provide these. Far from being esoteric, organic chemistry serves global needs.

\section{Five years on}

\section{Immigration restrictions imposed after 11 September 2001 have eased, but improvements must continue.}

T he attack of 11 September 2001 changed many things, including the way science is done in America. Before the attack, the United States was a focal point for scientists from around the world who went there to study, conduct research and teach. But in its aftermath, a series of restrictive new immigration measures led to lengthy delays for foreign researchers, and many were turned away. In 2004, we warned that these policies were strangling scientific exchange and could have dire consequences for the nation's scientific leadership (see Nature 427, 181; 2004).

As reported on page 6 of this issue, things have improved, although perhaps not as much as many researchers would have liked. The Department of State has boosted staffing levels at its embassies and consulates, and new computer systems are helping to prevent applications from becoming lost during interagency security reviews in Washington. Waiting times for those reviews are down from months to weeks: in Beijing, a student visa that might have taken six months can now be granted in just ten days.

The government has taken other positive steps, abandoning a plan to force foreign scientists to obtain licences to operate lab equipment (see Nature 441, 679; 2006), and revising a rule that would have required foreign-born researchers on defence-funded projects to work in 'segregated areas. These moves were in response to a vocal and concerted campaign by a coalition of scientific, university and industry organizations that warned policy-makers that such restrictions would not be in the nation's best interest.

Researchers entering the United States today still find it a hassle, but most feel that it is worth the trouble to come to US laboratories. New statistics are showing a resurgence of foreign students, and researchers are probably following, although numbers reflecting their movement are more difficult to obtain.

This could lead some to believe that the problem is largely solved. But more should be done to ensure free scientific exchange between the United States and other countries. Scientific groups in America should continue to press for better training of embassy staff, and for the hiring of more scientifically aware case-workers. They should work with the State Department and the Department of Homeland Security to try to bring some much-needed transparency to the visa process. It is unlikely that the security checks at the heart of many researchers' delays will become more open, but more could be done to communicate with those entering the United States about the status of their applications. Finally, scientific organizations should support immigration legislation that would make it easier for foreign scientists trained in US universities to remain after finishing their work.

All this should be done with an eye to keeping an open dialogue between scientists and the federal officials overseeing immigration. In the event of another attack on the United States, such lines of communication could help to ameliorate the immigration restrictions that would almost certainly follow. The United States is a linchpin of the global scientific enterprise, and it is in everybody's interest that it remain open for business. 